\title{
THE RELATIONSHIP BETWEEN QUALITY OF WORK LIFE AND LOCATION OF CROSS-TRAINING AMONG OBSTETRIC NURSES IN URBAN NORTHEASTERN ONTARIO, CANADA: A POPULATION-BASED CROSS SECTIONAL STUDY
}

\section{BEHDIN NOWROUZI ${ }^{1,2}$, NANCY LIGHTFOOT ${ }^{2,3}$, LORRAINE CARTER ${ }^{4}$, MICHEL LARIVIÈRE $^{2,5}$, ELLEN RUKHOLM ${ }^{6}$, ROBERT SCHINKE ${ }^{5}$, and DIANE BELANGER-GARDNER ${ }^{7}$}

${ }^{1}$ Laurentian University, Sudbury, Ontario, Canada

Interdisciplinary $\mathrm{PhD}$ Program

${ }^{2}$ Laurentian University, Sudbury, Ontario, Canada

Centre for Research in Occupational Safety and Health

${ }^{3}$ Laurentian University, Sudbury, Ontario, Canada

Northern Ontario School of Medicine, Schools of Rural and Northern Health, Social Work, and Human Sciences Division

${ }^{4}$ Nipissing University, North Bay, Ontario, Canada

Centres for Flexible Teaching and Learning

${ }^{5}$ Laurentian University, Sudbury, Ontario, Canada

School of Human Kinetics and Northern Ontario School of Medicine

${ }^{6}$ Laurentian University, Sudbury, Ontario, Canada

Centre for Rural and Northern and Health Research

${ }^{7}$ Health Sciences North, Sudbury, Ontario, Canada

\begin{abstract}
Objectives: The purpose of this mixed methods study was to examine the quality of work life of registered nurses working in obstetrics at 4 hospitals in northeastern Ontario and explore demographic and occupational factors related to nurses' quality of work life (QWL). Material and Methods: A stratified random sample of registered nurses $(\mathrm{N}=111)$ selected from the 138 eligible registered nurses (80.4\%) of staff in the labor, delivery, recovery, and postpartum areas at the 4 hospitals participated. Logistic regression analyses were used to consider QWL in relation to the following: 1) demographic factors, and 2) stress, employment status and educational attainment. Results: In the logistic regression model, the odds of a higher quality of work life for nurses who were cross trained (nurses who can work across all areas of obstetrical care) were estimated to be 3.82 (odds ratio $=3.82$, 95\% confidence interval: 1.01-14.5) times the odds of a higher quality of work life for nurses who were not cross trained. Conclusions: This study highlights a relationship between quality of work life and associated factors including location of cross-training among obstetrical nurses in northeastern Ontario. These findings are supported by the qualitative interviews that examine in depth their relationship to QWL. Given the limited number of employment opportunities in the rural and remote regions, it is paramount that employers and employees work closely together in creating positive environments that promote nurses' QWL.
\end{abstract}

Key words:

Occupational stress, Workplace environment, Registered nurses, Quality of work life, Rural and northern Canada, Cross-training

Received: August 27, 2014. Accepted: November 4, 2014.

Corresponding author: B. Nowrouzi, Laurentian University, 935 Ramsey Lake Road, Sudbury, ON, Canada (e-mail: bx_nowrouzi@laurentian.ca). 


\section{INTRODUCTION}

Quality of work life (QWL) influences the performance and commitment of employees in various sectors, including government, education, and health care [1,2]. In healthcare settings, QWL can contribute to other positive outcomes for both the healthcare providers and recipients of care (e.g., greater satisfaction) [3,4]. A high QWL has been reported to attract new employees and retain a workforce [5] and numerous studies have been conducted to identify the factors that contribute to nurses' QWL [6]. Thus, health organizations are actively seeking ways to ensure a high QWL for their employees [5]. A wide range of definitions for QWL exists [6]. Nevertheless, most studies viewed QWL as a subjective phenomenon that is affected by personal feelings and perceptions [7]. Some of these benefits include strengthened organizational commitment, improved quality of care, and increased productivity for both the individual employee and the organization [8-12]. In rural and Northern Canada, insufficient research has been undertaken on the practice environments of registered nurses in regards to their effects on retention. Overall, $18 \%$ of the Canadian population live in rural and remote areas served by $10.8 \%$ registered nurses (RNs) [13]. Moreover, Northern Ontario residents have higher rates of chronic diseases than the average provincial rate and have a higher proportion of the population that are overweight or obese [14]. Besides, a higher proportion of the population are heavy drinkers and smokers $[15,16]$. Retaining nurses in environments handicapped by staff shortages and high turnover not only affects health care workers but also directly influences the safety of health care and outcomes. Therefore, it is important to understand the work environments and QWL of these nurses in order to promote their retention.

Quality of work life affects not only job satisfaction, but also satisfaction in other life domains including: leisure, family, financial well-being, health, housing, friendships, education attainment, community engagement, neighbourhood interactions, spiritual well-being, the environment, and cultural and social status [17]. Furthermore, the association between work, non-work life domains [18], and workrelated stress [19] is also a factor in QWL [20]. Evidence has demonstrated that a negative quality of work-life situation is related to lack of work-life balance [20-22]. The elements distinguishing the quality of work life from the larger construct of quality of life include the impact of work on people and organizational effectiveness, as well as participatory organizational problem solving and decision making [23].

\section{Conceptual framework}

In this study, the Job Demand-Control-Support (JDCS) [24] framework was used to explore potential associations between QWL, stress, and location of crosstraining in the work environment.

In this study, a cross-trained nurse is one who is able to perform the job tasks and responsibilities of the 3 areas of the obstetrical unit, including labor, delivery, recovery, and postpartum (please see below for definition).

The JDCS has been used extensively in research of occupational stress over the last 20 years [25]. The framework also used an approach to data analysis and interpretation of the findings [25]. The framework focuses on 2 dimensions of the work environment: job demands and job control [24]. Job demands refer to work load operationalized as time pressure and role conflict [26]. Job control, which is sometimes called decision latitude, refers to the person's ability to control his or her work activities [26]. Decision latitude includes 2 components: skill discretion and decision authority [26]. The 2 dimensions of the JDCS represent a complex set of interactions between demand, control, and social factors that may impact health outcomes. According to the model, the highest strain occurs in a work environment when demands are high, control is low, and social support is low [26]. Social support at work, was later added to the model; as a result, 
the demand-control-support model was defined. This revised model postulates that the highest risk of illness is expected in employers with high demand, low control, and low social support in the workplace [27]. This additional component of the model emphasizes the psychological and social factors people experience in the work environment that are rooted in social and interpersonal relations. According to the JDCS model, jobs that utilize skills and provide control and a supportive work environment contribute to better psychological and physical health. Mentally demanding jobs with low levels of control and/or less supportive environments are detrimental to health [4]. Several nursing studies have identified that diminished control over workplace decisions results in elevated occupational stress levels [9,28]. Furthermore, this theoretical framework was used to guide data analysis and interpret findings.

The framework helps explain how occupational stress may be mitigated if nurses have greater job control and decision-making capacity. In nursing environments where this opportunity is afforded, the levels of occupational stress are lower [29]. In terms of quality of work life, studies have reported that increased job autonomy and job control is linked to higher QWL among nurses and allied health professionals [30,31].

It is hypothesized that location of cross-training will afford nurses with increased clinical competencies to work in all areas of the birthing unit and permit for greater decisionmaking capacity in the delivery of obstetrical care to their patients. It is further hypothesized that those nurses that experienced higher job control and lower job demands coupled with high social supports in the work environment would be more likely to experience better health outcomes, including having a higher QWL. Conversely, nurses who experience low job control, high job demands and low social supports in the workplace will experience negative health outcomes.

Nurses who cannot manage increasing workloads or working across different areas of obstetrical care may have also have their job demands increased. Moreover, they may not receive much support from their managers and as a result experience a lower quality of work life.

\begin{abstract}
Aims
The purpose of this mixed methods study was to examine the quality of work life of registered nurses working in obstetrics wards of 4 hospitals in Northeastern Ontario, and to explore factors influencing the nurses' QWL.
\end{abstract}

\section{ETHICAL CONSIDERATIONS}

Ethics approval was provided by the research ethics boards for the university and the 4 hospitals involved in the study.

\section{MATERIAL AND METHODS}

\section{Design}

This 2-part study used a mixed-method sequential explanatory [32] approach to examine the quality of work life, location of cross-training, and job stress experienced by nurses working in the labor, delivery, and post-partum areas of selected Northeastern Ontario cities. During the quantitative phase (phase I), randomly selected participants from each of the 4 selected hospitals in Northeastern Ontario (Sudbury, North Bay, Sault Ste. Marie, and Timmins) completed 3 self-administered questionnaires either in print or online. This was followed by semistructured interviews. The interviews were undertaken on the basis that they could generate proposed themes and so assist in the interpretation of the quantitative findings.

\section{Quantitative phase}

\section{Participants}

A total of 138 nurses were eligible to participate in the study, including 51 nurses in Sudbury, 31 nurses in North Bay, 32 nurses in Sault Ste. Marie, and 24 nurses in Timmins. The nurses' alphanumeric identifiers were stratified randomly by location of cross-training, and geographic location. 
Definition - location of cross-training

In our investigation, a cross-trained nurse in obstetrics is a nurse who is able to perform the job tasks and responsibilities of the 3 areas of the obstetrical unit including labor, delivery, recovery, and postpartum. Only nurses at Health Sciences North (51 participants) were cross-trained. The remaining nurses at North Bay Regional Health Centre (31 participants), Timmins and District Area Hospital (24 participants), and Sault Area Hospital (32 participants) were not cross-trained. Of the total 138 nurses at the 4 hospitals, $36.9 \%$ were cross-trained and $63 \%$ were not cross-trained.

\section{Data collection}

The 15-page questionnaire, available in English, included questions about 7 potential major sources of stress closely related to the conceptual categories of stress found in the nursing stress scale [33] (e.g., death and dying, conflict with physicians, inadequate preparation, lack of support, conflict with other nurses, workload, and uncertainty concerning treatment); demographic information; quality of work life (Work-Related Quality of Life Scale - WRQoL) [20]; occupational histories; and work ability. Work ability is defined as the workers' capacity to perform their work, and is measured by an index describing their health resources in relation to work demands $[34,35]$. Work ability was measured by the Work Ability Index [34,35] describing their health resources with regard to work demands and quality of work life (e.g., job and career satisfaction, general well-being, stress at work, control at work, home-work support, and working conditions).

\section{Outcome measures}

\section{Work-Related Quality of Life Scale (WRQoL)}

The Work-Related Quality of Life Scale (WRQoL) was selected as one of the measures used in the survey because it captures employment and non-employment facets of life, as well as more current issues such as occupational stress and QWL [20]. Test-retest of the total scale of the WRQoL was considered to have good reliability (0.9). Furthermore, the measure provides greater relevance to healthcare workplaces than any previous measure of WRQoL [20].

The WRQoL is a 24-item psychometric scale used to gauge the perceived quality of work by an employee based on 6 psychosocial sub-factors: job and career satisfaction, general well-being, homework interface, stress at work, control at work, and working conditions [20]. The WRQoL has 5 response options ranging from "strongly disagree" to "strongly agree." Individual item responses are added together to obtain a total score [20]. The scale captures employment and non-employment facets of life, as well as more current issues such as occupational stress. The construct validity of the WRQoL scale is supported by factor analysis [20]. Overall scale reliability for the item pool is strong with a Cronbach's $\alpha$ of 0.96 . This indicates that the items measure middle-range theoretical concepts in a consistent manner [20].

In this study, QWL was defined by the following statement taken from the Work Related Quality of Life Scale (WRQoL), Question 24: "I am satisfied with the overall quality of my working life." The possible responses were: "Strongly agree," "Agree," "Neutral," "Disagree" and "Strongly disagree." In addition, high QWL was defined as scores of 4 or 5, and low QWL was defined by scores of 3, 2, and 1 on a 5 point Likert scale by the WRQoL question 24: "I am satisfied with the overall quality of my working life."

\section{Nursing Stress Scale (NSS)}

The Nursing Stress Scale (NSS) [33] was also selected. The NSS is the most widely used and best known measure of stress for nurses [36]. The scale was designed around situations identified to cause stress for nurses in the performance of their duties. The NSS (Gray-Toft and 
Anderson, 1981) is 34 item scale. It has 4 response options ranging from "very frequently" to "never" and is divided into 7 subscales based on the concepts of psychological, physical, and social work environments. Good internal (0.79) consistency has been reported (Gray-Toft and Anderson, 1981). The NSS is the 1st measurement tool that addresses frequency of work stressors experienced by nurses. The scores are based on nurses' responses to descriptions of situations that have been identified as stressful for nurses in the workplace as well as stress in psychological, physical, and social work environments.

\section{Work Ability Index (WAI)}

The WAI Questionnaire was developed by researchers at the Finnish Institute of Occupational Health as an instrument for use in occupational health care [35]. Work ability is defined as the ability of a worker to perform his or her job, based on specific work demands, individual health conditions, and mental resources. The WAI uses point scales between 1 and 5, but varies for each factor [35]. A widely used 57-item scale, the WAI [35] is often used for evaluating nurses' work ability. An analysis of 10 European countries showed that the Cronbach's $\alpha$ for total sample amounted to 0.72 , while coefficients for national samples ranged from 0.54 for Slovakia to 0.79 for Finland [37].

\section{Demographic data}

In addition to the above tools, the questionnaire included demographic questions about: gender, ethnicity, age, education, and place of birth. The questionnaire also included questions about work settings such as: employment status, years of experience, types of shifts worked, patient workload, and hours worked per week.

\section{Data analysis}

Frequencies, percentages, cross-tabulations, and multivariate odds ratio estimates were computed using STATA 11.0 [38]. We did not have direct access to the list of participants. Each participant was assigned an alphanumeric number. Random selection of those alphanumeric numbers was done using the runiform function in STATA11.0 [38]. The unit manager was notified of the random number and instructed to ask the nurse (corresponding to that number) if she would consent to be contacted by myself to be included in the study. Assumptions and data were checked and met; there were no outliers.

Logistic regression models were fitted to provide estimates of multivariable odds ratio and corresponding $95 \%$ confidence intervals. Backward stepwise logistic regression analysis was performed by STATA, using a cut-off of $\mathrm{p}<0.05$ for inclusion. Binary logistic regression was performed, and QWL (e.g., low and high) was considered as the dependent dichotomous variable.

Four variables were included as independent variables: location of cross-training, total stress scores (total stress scores on NSS), employment status (full-time vs. parttime), and education attainment (RN Degree vs. RN Diploma). Potential factors, such as individual nurses' age, gender, ethnicity, place of birth, marital status, work ability, work absenteeism rates, education, and workload were also included [39]. In addition, we also included the 7 subscales of the NSS and the 6 subscales of the WRQoL.

Independent variables selected for logistic regression analysis were based on their relationship with intent to stay in their current position and QWL as reported in the literature [9,11,39-45]. In addition, Fisher's exact 2-tailed test was used to examine their relationship with QWL.

\section{Qualitative phase}

Participants

Recruitment of participants for the semi-structured interviews occurred through purposive sampling techniques. In the final question of the survey, interested respondents were invited to provide their e-mail address so they could be contacted about a follow-up interview. These individuals 
were contacted by email about the possibility of participating in an interview. Six 1-h interviews were conducted with nurses from the Health Sciences North $(\mathrm{N}=2)$, North Bay Regional Health Centre $(\mathrm{N}=2)$, and Sault Area Hospital in person $(\mathrm{N}=2)$. The interviews were audio recorded and transcribed verbatim. For completing the interview, participants received $\$ 20$.

Techniques of thematic analysis, most significantly coding for content, were used with the interview data [46]. The process was both inductive and deductive in nature and involved careful preparation of a code book, consultations with committee members, and, at times, recoding [47]. The outcomes of the analysis process were 5 themes and 1 level of subthemes; the 5 major themes were: workplace stress, relationships with colleagues, changes in care delivery and model of care, demands for resources, and QWL. While initial coding was principally descriptive in nature, as the analysis process progressed, it shifted to thematic and explanatory-based coding. Coding was facilitated through use of NVIVO 8 [48]. The transcription symbol "" was used to indicate phrase boundaries [49]. Capital letters were used to mark an increase in the voice tone relative to previous talk. Respondents were coded (R1, R2, R3, R4, R5 and R6).

\section{Rigor}

Rigor was ensured in 3 ways. The 1st involved the use of member checking after each interview. After a transcription was completed, the participant received a copy of the transcript by e-mail and was invited to make additions and/or changes for clarity and accuracy. Comments were returned either by email or phone. This feedback from the participants was vital to understanding the relationships between occupational stress, location of cross-training, and QWL. Member checking is a recognized means of error reduction [50].

The author also consulted with other members of the research team prior to and during the analysis process.
Agreement on the overall analysis strategy, coding categories, and the principal themes represent important commitment to the integrity of the study.

Finally, data collection and analysis were reflexive and iterative in nature. Being explicit and as self-aware as possible about personal assumptions, values and biases, and how they may come into play during the study contributed to the study's confirmability [51]. Clarity in the author's role coupled with data checks (e.g., for bias, deceit, informant knowledgeability, etc.) contributed to the study's reliability [51].

\section{Knowledge dissemination}

A summary of the findings was made available to the participants upon request and available for pickup at their respective hospital. This summary was mailed to the 4 obstetrics units, while presentations were made at each of the 4 hospital sites.

\section{RESULTS}

\section{Quantitative}

A total of 51 (45.9\% response rate) questionnaires were completed online while another 60 questionnaires $(54.1 \%$ response rate) were completed using the paper format $(\mathrm{N}=111)$. In total, 111 nurses completed the survey (80.4\% response rate). Fifty-one respondents (100\% response rate) at Health Sciences North completed the survey online. Twenty-two respondents (70.1\% response rate) at North Bay Regional Health Centre, 20 respondents (62.5\% response rate) at Sault Ste. Marie, and 18 respondents ( $75 \%$ response rate) at Timmins and District Hospital completed the paper version of the survey.

Table 1 presents a demographic profile of the nurses. The majority of participants were female (94.6\%), ranging in age from 24 to 64 years (mean $(\mathrm{M})=41.9$, standard deviation $(\mathrm{SD})=10.2)$. Forty-six percent of respondents worked in Sudbury at Health Sciences 
North; $19.8 \%$ worked in North Bay at North Bay Regional Health Centre; $18 \%$ worked in Sault Ste. Marie at Sault Area Hospital; and 16.2\% worked in Timmins at Timmins and District Hospital. The nurses had, on average, 16.3 years $(\mathrm{SD}=10.8)$ of nursing experience and 11.6 years $(\mathrm{SD}=9.01)$ of obstetrical nursing experience. Sixty-three percent of respondents worked full-time, 33\% worked part-time, and $4.5 \%$ were casual workers. The majority of respondents $(68.2 \%)$ described their ethnicity as English-Canadian. Approximately $25.8 \%$ of respondents self-identified as Francophone and $3 \%$ of the sample described their ethnicity as a combination of 2 ethnicities, such as French and Aboriginal.

Fisher's exact 2-tailed test was used to examine simple significance of the association between QWL and location of cross-training, NSS total stress scores, type of hospital (e.g., teaching vs. community hospital), and employment status. Fisher's exact 2-tailed test analysis revealed a statistically significant association between QWL and location of cross-training, NSS total stress scores, type of hospital (teaching vs. community hospital), and employment status. Cross-trained nurses were more likely to report a higher QWL $(\mathrm{N}=111, \mathrm{p}<0.01)$ than non-crosstrained nurses. Respondents with NSS total stress scores over 65 were likely to experience lower QWL ( $\mathrm{N}=111$, $\mathrm{p}<0.01)$. Full-time employees also reported higher QWL than part-time employees $(\mathrm{N}=88, \mathrm{p}<0.004)$. Fisher's exact testing done for other variables (e.g., place of birth, gender, ethnicity, education attainment, work absenteeism, years of experience, mean hours worked per week, and overtime hours worked per week) were not found to be statistically significant.

\section{Multivariable factors associated with obstetrical RN QWL}

The following variables in the multivariable logistic model were considered in relation to the outcomes of either high or low QWL: location of cross-training, age, occupational stress, income, employment status, and type of hospital (e.g., teaching or community hospital). High quality of work life was defined as scores of 4 or 5 and low quality of work life was defined by scores of 3,2 and 1 on a 5 point Likert scale by the WRQLS question 24: "I am satisfied with the overall quality of my working life."

Unadjusted odds ratio estimates for study participant characteristics are found in Table 2. Both significant and insignificant variables were included in the simple model. Variables statistically significantly related to work ability were as follows: cross-trained nurses $(\mathrm{OR}=5.32,95 \% \mathrm{CI}$ : 1.84-15.4), total stress scores of non-cross trained nurses $(\mathrm{OR}=0.20,95 \%$ CI: $0.07-0.59)$, and part-time employment status (OR $=0.13,95 \%$ CI: $0.29-0.62)$.

Nurses who were cross-trained were over 5 times as likely as non-cross-trained nurses to have a high QWL. Nurses with total stress scores greater than 65 were 5 times as likely to experience low QWL. Part-time employed nurses were more than 7 times as likely to have low QWL.

Multivariate odds ratio estimates for study participant characteristics are found in Table 3. Quality of work life was considered as a dependent dichotomous variable. Cross-trained nurses were 3.82 times (95\% CI: 1.01-14.5) more likely to have a higher quality of work life than noncross trained nurses. The other variables (e.g., total stress scores, employment status and education attainment) were not statistically significant. Similarly, analysis of the subscales of the WRQoL and the NSS were not statistically significant with our variables of interest used in relation to either high or low QWL.

Analysis of the semi-structured interviews yielded 5 core themes: workplace stress, relationships with colleagues, changes in care delivery and model of care, demands for resources, and QWL.

The majority of the study respondents spoke about the stressors of their work environment. These stressors included the actual work the nurses do as well as their 
Table 1. Characteristics of study group

\begin{tabular}{|c|c|c|c|c|c|}
\hline \multirow{2}{*}{ Variable } & \multirow{2}{*}{$\begin{array}{c}\text { Respondents } \\
(\mathrm{N}=111) \\
{[\mathrm{n}(\%)]}\end{array}$} & \multicolumn{4}{|c|}{$\begin{array}{l}\text { Study group } \\
{[\mathrm{n}(\%)]}\end{array}$} \\
\hline & & HSN & NBRHC & SAH & $\mathrm{TDH}$ \\
\hline \multicolumn{6}{|l|}{ Gender } \\
\hline female & $87(94.6)$ & $50(98.0)$ & $18(94.8)$ & $12(100)$ & $7(70.0)$ \\
\hline male & $5(5.4)$ & $1(2.0)$ & $1(5.2)$ & $0(0.0)$ & $3(30.0)$ \\
\hline \multicolumn{6}{|l|}{ Age [years] } \\
\hline$<35$ & $20(24.4)$ & $10(22.2)$ & $5(35.7)$ & $4(28.6)$ & $1(11.1)$ \\
\hline $35-44$ & $29(35.3)$ & $18(40.0)$ & $4(28.6)$ & $3(21.4)$ & $4(44.4)$ \\
\hline $45-54$ & $19(23.2)$ & $12(26.7)$ & $2(14.3)$ & $4(28.6)$ & $1(11.1)$ \\
\hline$\geq 55$ years & $14(17.1)$ & $5(11.1)$ & $3(21.4)$ & $3(21.4)$ & $3(33.3)$ \\
\hline \multicolumn{6}{|l|}{ Nursing experience [years] } \\
\hline$\leq 10$ & $29(34.1)$ & $16(33.3)$ & $6(37.5)$ & $5(38.5)$ & $2(25.0)$ \\
\hline $11-20$ & $26(30.6)$ & $18(37.5)$ & $4(25.0)$ & $2(15.4)$ & $2(25.0)$ \\
\hline$>20$ & $30(35.3)$ & $14(29.2)$ & $6(37.5)$ & $6(46.2)$ & $4(50.0)$ \\
\hline \multicolumn{6}{|l|}{ Marital status } \\
\hline married/common-law & $69(78.4)$ & $38(77.6)$ & $11(64.7)$ & $11(84.6)$ & $9(100)$ \\
\hline single & $9(10.2)$ & $5(10.2)$ & $3(17.6)$ & $1(7.7)$ & $0(0.0)$ \\
\hline divorced & $5(5.7)$ & $2(4.1)$ & $2(11.8)$ & $1(7.7)$ & $0(0.0)$ \\
\hline separated & $3(3.4)$ & $3(6.1)$ & $0(0.0)$ & $0(0.0)$ & $0(0.0)$ \\
\hline widowed & $2(2.3)$ & $1(2.0)$ & $1(5.9)$ & $0(0.0)$ & $0(0.0)$ \\
\hline \multicolumn{6}{|l|}{ Born northeastern Ontario } \\
\hline yes & $84(92.3)$ & $48(100)$ & $8(80.0)$ & $17(94.4)$ & $11(73.3)$ \\
\hline no & $7(7.7)$ & $0(0.0)$ & $2(20.0)$ & $1(5.6)$ & $4(26.7)$ \\
\hline \multicolumn{6}{|c|}{$\begin{array}{l}\text { Was your spouse/significant other born } \\
\text { and/or raised in northeastern Ontario? }\end{array}$} \\
\hline yes & $69(85.2)$ & $39(86.7)$ & $12(80.0)$ & $10(76.9)$ & $8(100)$ \\
\hline no & $7(8.6)$ & $3(6.7)$ & $3(3.0)$ & $1(7.7)$ & $0(0.0)$ \\
\hline not applicable & $5(6.2)$ & $3(6.7)$ & $0(0.0)$ & $2(15.4)$ & $0(0.0)$ \\
\hline \multicolumn{6}{|c|}{ Highest attained nursing education } \\
\hline RN diploma & $50(45.0)$ & $32(64.0)$ & $14(63.6)$ & $2(9.5)$ & $2(11.1)$ \\
\hline RN university degree & $59(53.2)$ & $17(34.0)$ & $7(31.8)$ & $19(90.5)$ & $16(88.9)$ \\
\hline masters & $2(1.8)$ & $1(2.0)$ & $1(4.5)$ & $0(0.0)$ & $0(0.0)$ \\
\hline \multicolumn{6}{|l|}{ Ethnicity } \\
\hline English-Canadian & $58(68.2)$ & $25(53.2)$ & $14(82.4)$ & $11(84.6)$ & $8(80.0)$ \\
\hline francophone & $22(25.8)$ & $18(38.3)$ & $2(11.8)$ & $0(0.0)$ & $2(20.0)$ \\
\hline aboriginal & $3(3.5)$ & $2(4.3)$ & $1(5.9)$ & $1(7.7)$ & $0(0.0)$ \\
\hline other & $2(2.5)$ & $2(4.3)$ & $0(0.0)$ & $0(0.0)$ & $0(0.0)$ \\
\hline
\end{tabular}

HSN - Health Sciences North; NBRHC - North Bay Regional Health Centre; SAH - Sault Area Hospital; TDH - Timmins and District Hospital; $\mathrm{RN}$ - registered nurse. 
Table 2. Unadjusted odds ratio estimates and approximate $95 \%$ confidence intervals for location of cross-training, total stress scores, employment status and education attainment

\begin{tabular}{|c|c|c|c|c|}
\hline \multirow[t]{2}{*}{ Variable } & \multicolumn{2}{|c|}{$\begin{array}{l}\mathrm{QWL}^{\mathrm{b}} \\
{[\mathrm{n}(\%)]}\end{array}$} & \multirow[t]{2}{*}{ OR estimate } & \multirow[t]{2}{*}{$95 \% \mathrm{CI}$} \\
\hline & low & high & & \\
\hline \multicolumn{5}{|l|}{ Location of cross-training } \\
\hline no (Sault Ste. Marie, North Bay, Timmins) & $22(81.5)$ & $38(45.2)$ & 1.00 & \\
\hline yes (HSN) & $5(18.5)$ & $46(54.8)$ & 5.32 & $1.84-15.40$ \\
\hline \multicolumn{5}{|l|}{ Total stress score ${ }^{a}$} \\
\hline low (total score $<65$ ) & $5(10.6)$ & $19(37.3)$ & 1.00 & \\
\hline high (total score $>65$ ) & $42(89.4)$ & $32(62.8)$ & 0.20 & $0.07-0.59$ \\
\hline \multicolumn{5}{|l|}{ Employment status } \\
\hline FT & $18(90.0)$ & $37(54.4)$ & 1.00 & \\
\hline PT & $2(10.0)$ & $31(45.6)$ & 0.13 & $0.29-0.62$ \\
\hline \multicolumn{5}{|l|}{ Education attainment } \\
\hline RN degree & $17(27.9)$ & $44(72.1)$ & 1.00 & \\
\hline RN diploma & $10(20.0)$ & $40(80.0)$ & 1.55 & $0.63-3.77$ \\
\hline
\end{tabular}

HSN - Health Sciences North; FT - full-time; PT - part-time; RN - registered nurse; QWL - quality of work life; OR - odds ratio; CI - confidence interval.

${ }^{a}$ The total nursing stress scale (NSS) stress score was partitioned into 2 groups based on the median value $(\mathrm{Me}=65)$. Respondents with scores $<65$ were characterized as the low stress group and those with scores $\geq 65$ were placed in the high stress group.

${ }^{b}$ High quality of work life was defined as scores of 4 or 5 and low quality of work life was defined by scores of 3,2 and 1 on a 5 point Likert scale by the WRQLS question 24: "I am satisfied with the overall quality of my working life."

Table 3. Multivariable adjusted odds ratio estimates and approximate $95 \%$ confidence intervals for registered nurse quality of work life

\begin{tabular}{|c|c|c|c|c|}
\hline \multirow[t]{2}{*}{ Variable } & \multicolumn{2}{|c|}{$\begin{array}{l}\mathrm{QWL}^{\mathrm{b}} \\
{[\mathrm{n}(\%)]}\end{array}$} & \multirow[t]{2}{*}{ OR estimate } & \multirow[t]{2}{*}{$95 \% \mathrm{CI}$} \\
\hline & low & high & & \\
\hline \multicolumn{5}{|l|}{ Location with cross-training } \\
\hline no (Sault Ste. Marie, North Bay, Timmins) & $22(81.5)$ & $38(45.2)$ & 1.00 & \\
\hline yes (HSN) & $5(18.5)$ & $46(54.8)$ & $3.82 *$ & $1.01-14.5$ \\
\hline missing & 0 & 0 & & \\
\hline \multicolumn{5}{|l|}{ Total stress scores } \\
\hline low (total score $<65$ ) & $5(10.6)$ & $19(37.3)$ & 1.00 & \\
\hline high (total score $\geq 65$ ) & $42(89.4)$ & $32(62.8)$ & 0.95 & $0.88-1.01$ \\
\hline missing & 5 & 8 & & \\
\hline \multicolumn{5}{|l|}{ Employment status } \\
\hline FT & $18(90.0)$ & $37(54.4)$ & 1.00 & \\
\hline PT & $2(10.0)$ & $31(45.6)$ & 0.27 & $0.04-1.55$ \\
\hline missing & 10 & 13 & & \\
\hline
\end{tabular}


Table 3. Multivariable adjusted odds ratio estimates and approximate $95 \%$ confidence intervals for registered nurse quality of work life - cont.

\begin{tabular}{|c|c|c|c|c|}
\hline \multirow[t]{2}{*}{ Variable } & \multicolumn{2}{|c|}{$\begin{array}{l}\mathrm{QWL}^{\mathrm{b}} \\
{[\mathrm{n}(\%)]}\end{array}$} & \multirow{2}{*}{ OR estimate } & \multirow[t]{2}{*}{$95 \% \mathrm{CI}$} \\
\hline & low & high & & \\
\hline \multicolumn{5}{|l|}{ Education attainment } \\
\hline RN degree & $17(27.9)$ & $44(72.1)$ & 1.00 & \\
\hline RN diploma & $10(20.0)$ & $40(80.0)$ & 1.63 & $0.33-8.05$ \\
\hline missing & 0 & 0 & & \\
\hline
\end{tabular}

Abbreviations as in Table 2.

$*<\mathrm{p}<0.05$

relationships with colleagues. One respondent offered the following insight into the pressure she experienced from physicians and her nurse-manager: "They [the physicians] you know / and they'll even go to the managers who tell us »no no there's only 3 of them « and that's what it's supposed to be but if they buck enough the physicians and they go and talk to the manager they can't really stop them. It could be like 11 at night and they're still wanting to push these inductions. So that's kind of stressful" (R3). Another theme discovered in the interviews was the need for relationships. While relationships can refer to the interactions between colleagues in a social setting, for nurses, relationships can also be an important part of the teamwork required to provide safe patient care. One respondent shared the following about her relationships with colleagues and how they progressed from limited interactions to more collegial exchanges. Moreover, when the relationships were stronger, work was improved: "Even though you know that's intimidating when you start a new job, you don't know people and sometimes you don't want to go to these functions by yourself but after doing that a few times I found that I got to know people better and they were even more kind of friendly towards you in the work setting which helped your work life that way" (R2).

All respondents commented on the quality of their work lives. Given that job satisfaction and overall happiness at work were reported by the nurses, the take away is that, in general, the nurses enjoyed positive work lives. One respondent reflected on her work setting in the following way: "Well it's usually a good floor to work on, it's usually a happy environment and you get to share in people's like probably the best experience of their life is having their 1st baby, or 2nd or 3rd. I guess why I enjoy working there" (R2).

The majority of the nurses said that location of crosstraining was beneficial and that it helped increase clinical competency. In this study, the term cross training refers to being competent to provide care in all aspects of obstetric care. The passage below presents one instance through which clinical competence was augmented: "Um, I don't know necessarily which AREA of cross-training was more challenging, I mean learning how to take care of a lady in labor and as she's delivering a baby I found you know stressful and challenging at 1st because it was completely new to me. But, it was never to the point that I, I didn't enjoy it, I still, I enjoyed it even during the training part" (R1).

\section{DISCUSSION}

The purpose of this mixed methods study was to examine the quality of work life of registered nurses working in obstetrics at 4 hospitals in Northeastern Ontario and to explore factors influencing the nurses' quality of work life (QWL). 
The association between a high QWL and location of cross-training emphasizes the importance of positive workplace conditions for nurses' QWL and for their empowerment. At the same time, the statistically significant odds ratio may have been influenced by selection bias since nurses who did not want to participate in crosstraining had left the unit before its implementation. Furthermore, in this study, all nurses who were crosstrained were located at Health Sciences North and thus other factors may have contributed to their high QWL. For instance, several organizational characteristics including social support by management during the crosstraining transition period may have played a significant role in promoting cross-training. Moreover, educational and career opportunities may be more readily available in Sudbury and contributed to a higher QWL in these cross-trained nurses.

From the qualitative interviews, we found that the location of cross-training provided both positive and negative aspects of nurses work environment. The negative implications of the location of cross-training may include increased clinical responsibilities and higher workloads. It is important to state that the interviews served to explain and provide greater depth to the quantitative findings.

The lack of resources was identified by some of the nurses as a source of stress because looking for equipment took up a great deal of their time. It also acted as a barrier in training student nurses and in providing care to families. Others stated that during the period of transition, in which nurses begin cross-training, there were feelings of apprehension, stress and anxiety. The negative implications of the location of cross-training may be mitigated through skillful management.

Many of the potentially negative impacts stem from poor planning and implementations of cross-training [52]. Some research suggests that if managed strategically and with care, cross-training should provide a net benefit for patients, their families, nurses, and employers [52].
This study's results focus on nurses in small, urban, Northern Ontario and provide insight into their occupational health and work settings. This is in contrast to numerous studies that have examined occupational stress among nurses in large metropolitan urban areas in Canada [53], the United States [54], Europe [55-57], Australia [56], India [58], and China [59]. The QWL of nurses working in northern communities may reflect distinct characteristics such as a rural and northern lifestyle and a greater sense of belonging to a community than the QWLs of nurses working in large metropolitan areas do. Since individuals in rural and northern regions have been reported to value self-sufficiency, self-reliance, independence, and stoicism, these concepts may also influence the results in this study [60]. This idea merits investigation.

We believe there is a need for additional research to explore the work environment of nurses and its relationship to their health and well-being.

Rural and Northern Ontario communities have unique challenges in creating, recruiting, and retaining an adequate health care workforce and, in particular, primary health care nurses. With many nurses approaching retirement and fewer individuals entering the profession, nursing is experiencing a serious workforce shortage [61]. The physical and psychosocial stressors of nursing may be greater in rural and northern settings. Rural and northern areas of most northern countries have a severe shortage of health care professionals, including nurses. Those working in these regions face higher workloads, must work with less resources and have fewer opportunities for career and educational advancement [28,62]. Exacerbating the situation is that rural and northern residents are, on average, sicker [63] and have to travel greater distances to receive services, including health services, compared to residents in Southern Ontario. Broadly, this study can be added to a growing body of knowledge related to healthy work environments in public and private industries. 
The aforementioned quantitative findings are largely in line with the viewpoints expressed in the interviews. Crosstraining may be better supported by workers with greater organizational supports and those that have opportunities to expand both their career and educational prospective.

In relation to participants' views about workplace stress, 2 key points emerged. Firstly, elevated workloads, and unpredictability of the occupation (labor can occur at any time) were sources of physical and mental stress for the majority of the respondents. Secondly, interventions that mitigate occupational stressors (e.g., acute low back pain, burnout, job dissatisfaction, depression) may result in healthier workers and a more positive work environment [63-65]. As knowledge expands in the field of occupational stress and health, different kinds of interventions will need to be identified. Replication of this study with larger and more diverse samples, including managers, is warranted.

This research provides preliminary evidence regarding the work environment of nurses in Northeastern Ontario as it relates the relationship between cross-training and QWL. These results support the proposal that given the limited number of employment opportunities in the north, employers and employees need to work together to create a positive workplace that fosters work environments that promote higher QWL levels. In terms of policy implications, the recruitment and retention of nurses to northern and rural areas is a serious undertaking for decision makers and planners. Building positive work environments is a crucial component of retaining health care professionals in the north and recruiting those from other regions to move here for lifestyle and career opportunities [9,64,66,67].

The overall response rate (80.4\%) was good. However, the sample size might have been increased by augmenting the remuneration provided in the study, lengthening the data collection period, and inviting all nurses at each site to participate in the study. There are several limitations in this study. Firstly, the representativeness of participants in this study is of potential concern.

The sample population was confined to 4 selected Northeastern Ontario hospitals such that the results are not generalizable to other obstetric nurses in other parts of Ontario. Secondly, those nurses who had left obstetrics were not reflected in the sample and may provide a different view of the relationship between QWL and cross-training. Selection bias may have influenced the study results. Thirdly, location of cross-training showed a statistical relationship with a high QWL, but included only nurses crosstrained at 1 hospital location (Sudbury location).

Given this circumstance, location of cross-training as a possible factor in decreasing stress and enhancing quality of work life requires further investigation. Hospital size, size of the community, continuing education opportunities, organizational structure and leadership, are some additional factors meriting investigation for their possible impact on quality of work life and stress among nurses. Finally, the study outcome (i.e., high QWL) was prevalent and not rare, therefore, the multivariable odds ratio estimates may be an overestimation of the relative risk.

\section{CONCLUSIONS}

The present study highlights the relationship between factors associated (location of cross-training) with QWL of registered nurses working in 4 small urban hospital-based obstetric programs. Additional research is needed to further examine the relationship between QWL and related factors. These may ultimately lead to the development and implementation of QWL programs that are tailored to meet the needs of employees and employers. The study highlights the importance of establishing a high QWL for nurses' health. Moreover, it provides preliminary evidence of the work environment of obstetrical nurses working in northeastern Ontario and potential opportunities for interventions to increase their QWL. 
Interventions that target organizational and manager characteristics as well as approaches that ameliorate nurses working conditions have been shown to increase QWL and may lead to healthier work environments $[9,68]$. Since all cross-trained nurses were located at 1 hospital, future studies need to examine cross-training across multiple hospital sites to provide greater evidence of its relationship with QWL. Analysis by geographic location will allow for a better elucidation of the relationship between crosstraining and QWL. Moreover, given the circumstance that only 1 site received cross-training, other factors including hospital size, population of the community, career and education opportunities available in the workplace, organizational structure and leadership qualities may be additional variables to examine for their potential relationship with QWL.

\section{REFERENCES}

1. Nembhard D. 'Work memory' affects scheduling success. Inst Ind Eng Solutions. 2001;33(12):15.

2. Huang TC, Lawler J, Lei CY. The effects of quality of work life on commitment and turnover intention. Soc Behav Personal. 2007;35(6):735-50, http://dx.doi.org/10.2224/ sbp.2007.35.6.735.

3. Lu H, Barriball KL, Zhang X, While AE. Job satisfaction among hospital nurses revisited: A systematic review. Int J Nurs Stud. 2012;49(8):1017-38, http://dx.doi. org/10.1016/j.ijnurstu.2011.11.009.

4. Almalki MJ, FitzGerald G, Clark M. The relationship between quality of work life and turnover intention of primary health care nurses in Saudi Arabia. BMC Health Serv Res. 2012;12(1):314, http://dx.doi.org/10.1186/1472-6963-12-314.

5. Akdere M. Improving quality of work-life: Implications for human resources. Bus Rev. 2006;6(1):173-7.

6. Vagharseyyedin SA, Vanaki Z, Mohammadi E. The nature nursing quality of work life: An integrative review of literature. West J Nurs Res. 2011;33(6):786-804, http://dx.doi. org/10.1177/0193945910378855.
7. Brooks BA, Storfjell J, Omoike O, Ohlson S, Stemler I, Shaver J, et al. Assessing the quality of nursing work life. Nurs Adm Q. 2007;31(2):152-7, http://dx.doi.org/10.1097/01. NAQ.0000264864.94958.8e.

8. Royuela V, López-Tamayo J, Suriñach J. Results of a Quality of Work Life Index in Spain. A comparison of survey results and aggregate social indicators. Soc Indic Res. 2009;90(2):225-41, http://dx.doi.org/10.1007/s11205008-9254-3.

9. Golubic R, Milosevic M, Knezevic B, Mustajbegovic J. Work-related stress, education and work ability among hospital nurses. J Adv Nurs. 2009;65:2056-66, http://dx.doi. org/10.1111/j.1365-2648.2009.05057.x.

10. Sale J. Perceptions of a quality of work-life survey from the perspective of employees in a Canadian cancer centre. Qual Quant. 2007;41(6):779-91, http://dx.doi.org/10.1007/ s11135-006-9025-7.

11. Saraji GN, Dargahi H. Study of quality of work life (QWL). Iran J Public Health. 2006;35(4):8-14.

12. Rossi AM. Occupational stressors and gender differences. In: Rossi AM, Perrewe PL, Sauter SL, editors. Stress and quality of working life: Current perspectives in occupational health. Porto Alegre, Brazil: Information Age Publishing, Inc.; 2006. p. 9-37.

13. MacLeod MLP, Pitblado JR, Koren I, Stewart NJ, Kulig JC. Planning for the regulated nursing workforce in rural and small town Canada. 2013 Annual CAHSPR Conference; 2013 May 28-31; Vancouver, BC, Canada. Vancouver: Canadian Association of Health Services and Policy Research; 2013.

14. Ministry of Health and Long Term Care. Rural and northern health care framework. Toronto (ON): Ministry, Government of Ontario, Canada; 2011.

15. North West Local Health Integration Network. Integrated Health Services Plan. Thunder Bay (ON): North West Local Health Integration Network; 2013.

16. North East Local Health Integration Network. Integrated Health Service Plan. North Bay (ON): North East Local Health Integration Network; 2013. 
17. Macik-Frey M. Advances in occupational health: From a stressful beginning to a positive future. J Manag. 2007; 33(6):809-40, http://dx.doi.org/10.1177/0149206307307634.

18. Loscocco KA, Roschelle AR. Influences on the quality of work and nonwork life: Two decades in review. J Vocat Behav. 1991;39(2):182-225, http://dx.doi.org/10.1016/00018791(91)90009-B.

19. Killian JG. Career and technical education teacher burnout: Impact of humor-coping style and job-related stress [Ph.D. thesis]. Carbondale: Southern Illinois University; 2004.

20. Van Laar D, Edwards JA, Easton S. The Work-Related Quality of Life scale for healthcare workers. J Adv Nurs. 2007;60(3):325-33, http://dx.doi.org/10.1111/j.1365-26 48.2007.04409.x

21. Spreitzer G. Psychological empowerment in the workplace: Dimensions, measurement, and validation. Acad Manage J. 1995;38(5):1442-62, http://dx.doi.org/10.2307/ 256865 .

22. Pino O, Rossini G. Perceived organizational stressors and interpersonal relationships as predictors of job satisfaction and well-being among hospital nurses. Int J Psychol Behav Sci. 2012;2(6):196-207, http://dx.doi.org/10.5923/j.ijpbs.2012 0206.02 .

23. Nadler DA, Lawler EE. Quality of work life: Perceptions and direction. Organ Dyn. 1983;11(3):20-30, http://dx.doi. org/10.1016/0090-2616(83)90003-7.

24. Karasek RA Jr. Job demands, job decision latitude, and mental strain: Implications for job redesign. Admin Sci Quart. 1979;24(2):285-308, http://dx.doi.org/10.2307/ 2392498.

25. Häusser JA, Mojzisch A, Niesel M, Schulz-Hardt S. Ten years on: A review of recent research on the Job Demand-Control (-Support) model and psychological wellbeing. Work Stress. 2010;24(1):1-35, http://dx.doi.org/ 10.1080/02678371003683747.

26. Karasek RA. Job Content Instrument: Questionnaire and user's guide. Los Angeles (CA): University of South California; 1985.
27. Pasca R, Wagner SL. Occupational stress in the multicultural workplace. J Immigr Minor Health. 2011;13(4):697-705, http://dx.doi.org/10.1007/s10903-011-9457-6.

28. Opie T, Dollard M, Lenthall S, Wakerman J, Dunn S, Knight S, et al. Levels of occupational stress in the remote area nursing workforce. Aust J Rural Health. 2010;18(6): 235-41, http://dx.doi.org/10.1111/j.1440-1584.2010.01161.x.

29. Henderson Betkus M, MacLeod MLP. Retaining public health nurses in rural British Columbia: The influence of job and community satisfaction. Can J Public Health. 2004;95(1):54-8.

30. Cole DC, Robson LS, Lemieux-Charles L, McGuire W, Sicotte C, Champagne F. Quality of working life indicators in Canadian health care organizations: A tool for healthy, health care workplaces? Occup Med (Lond). 2005;55(1): 54-9, http://dx.doi.org/10.1093/occmed/kqi009.

31. Solomon P, Salvatori P, Berry S. Perceptions of important retention and recruitment factors by therapists in northwestern Ontario. J Rural Health. 2001;17(3):278-85, http://dx.doi.org/10.1111/j.1748-0361.2001.tb00965.x.

32. Creswell JW. Research design: Qualitative, quantitative, and mixed methods approaches. Lincoln: Sage Publications, Inc; 2013.

33. Gray-Toft P, Anderson JG. The Nursing Stress Scale: Development of an instrument. J Psychopathol Behav Assess. 1981;3(1):11-23， http://dx.doi.org/10.1007/BF01 321348 .

34. Tuomi K, Ilmarinen J, Jahkola A, Katajarinne L, Tulkki A. Work Ability Index. Helsinki: Finnish Institute of Occupational Health; 1998.

35. Tuomi K, Ilmarinen J, Jahkola A, Katajarinne L, Tulkki A. Work Ability Index. Helsinki: Finnish Institute of Occupational Health; 1994.

36. French SE, Lenton R, Walters V, Eyles J. An empirical evaluation of an expanded Nursing Stress Scale. J Nurs Meas. 2000;8:161-78.

37. Radkiewicz P, Widerszal-Bazyl M; the Next-Study group. Psychometric properties of Work Ability Index in the light 
of comparative survey study. Int Congr Ser. 2005;1280: 304-9, http://dx.doi.org/10.1016/j.ics.2005.02.089.

38. StataCorp. Stata statistical software: Release 11.0 [computer program]. College Station, TX: Stata Corporation; 2009.

39. McNeely E. The consequences of job stress for nurses' health: Time for a check-up. Nurs Outlook. 2005;53(6): 291-9, http://dx.doi.org/10.1016/j.outlook.2005.10.001.

40. Rice B, Snyder A. Reconciliation in the context of a settler society: Healing the legacy of colonialism in Canada. In: Castellano MB, Archibald L, DeGagné M, editors. Speaking my truth. Ottawa, Canada: Aboriginal Healing Foundation; 2008. p. 43-63.

41. Frankel B, Speechley M, Wade T. The sociology of health and health care: A Canadian perspective. Toronto: Copp Clark; 1996.

42. Gunnarsdottir S, Clarke SP, Rafferty AM, Nutbeam D. Front-line management, staffing and nurse-doctor relationships as predictors of nurse and patient outcomes. A survey of Icelandic hospital nurses. Int J Nurs Stud. 2009; 46(7):920-7, http://dx.doi.org/10.1016/j.jinurstu.2006.11.007.

43. Stordeur S, D’Hoore W, Vandenberghe C. Leadership, organizational stress, and emotional exhaustion among hospital nursing staff. J Adv Nurs. 2001;35(4):533-42, http://dx.doi. org/10.1046/j.1365-2648.2001.01885.x.

44. Martel JP, Dupuis G. Quality of work life: Theoretical and methodological problems, and presentation of a new model and measuring instrument. Soc Indic Res. 2006;77(2): 333-68, http://dx.doi.org/10.1007/s11205-004-5368-4.

45. Vagharseyyedin SA, Vanaki Z, Mohammadi E. The nature nursing quality of work life. An integrative review of literature. West J Nurs Res. 2011;33(6):786-804, http://dx.doi. org $/ 10.1177 / 0193945910378855$.

46. Guest G, MacQueen KM, Namey EE. Applied thematic analysis. Los Angeles (CA): Sage; 2012, http://dx.doi.org/10. 4135/9781483384436.

47. Burns B, Grove SK. The practice of nursing research: Conduct, critique, and utilization. St. Louis, Missouri: Elsevier Saunders; 2005.
48. QSR. NVivo Version 8 for Windows [computer program]. Doncaster, Australia: QSR International Pty Ltd; 2007.

49. Bailey PH, Tilley S. Storytelling and the interpretation of meaning in qualitative research. J Adv Nurs. 2002;38(6): 574-83, http://dx.doi.org/10.1046/j.1365-2648.2000.02224.x.

50. Mays N, Pope C. Assessing quality in qualitative research. BMJ. 2000;320(7226):50-2, http://dx.doi.org/ 10.1136/bmj.320.7226.50.

51. Miles MB, Huberman AM. Qualitative data analysis: An expanded sourcebook. Thousand Oaks: Sage Publications; 1994.

52. Schultz KL, McClain JO, Thomas LJ. Overcoming the dark side of worker flexibility. J Oper Manag. 2003;21(1):81-92, http://dx.doi.org/10.1016/S0272-6963(02)00040-2.

53. Tyson PD, Pongruengphant R, Aggarwal B. Coping with organizational stress among hospital nurses in Southern Ontario. Int J Nurs Stud. 2002;39(4):453-9, http://dx.doi. org/10.1016/S0020-7489(01)00047-5.

54. Ulrich C, O'Donnell P, Taylor C, Farrar A, Danis M, Grady C. Ethical climate, ethics stress, and the job satisfaction of nurses and social workers in the United States. Soc Sci Med. 2007;65(8):1708-19, http://dx.doi.org/10.1016/ j.socscimed.2007.05.050.

55. Sveinsdottir H, Biering P, Ramel A. Occupational stress, job satisfaction, and working environment among Icelandic nurses: A cross-sectional questionnaire survey. Int J Nurs Stud. 2006;43(7):875-89.

56. Linder-Pelz S, Pierce JP, Minslow M. Occupational stress in nurses in an Australian general hospital. Community Health Stud. 1986;10(3):307-16, http://dx.doi.org/10.1111/ j.1753-6405.1986.tb00113.x.

57. Guppy A, Gutteridge T. Job satisfaction and occupational stress in UK general hospital nursing staff. Work Stress. 1991;5(4):315-23, http://dx.doi.org/10.1080/0267837 9108257029.

58. McVicar A. Workplace stress in nursing: A literature review. J Adv Nurs. 2003;44(6):633-42, http://dx.doi.org/10. 1046/j.0309-2402.2003.02853.x. 
59. Wu H, Chi TS, Chen L, Wang L, Jin YP. Occupational stress among hospital nurses: Cross-sectional survey. J Adv Nurs. 2010;66(3):627-34, http://dx.doi.org/10.1111/ j.1365-2648.2009.05203.x.

60. Lightfoot N, Strasser R, Maar M, Jacklin K. Challenges and rewards of health research in northern, rural, and remote communities. Ann Epidemiol. 2008;18(6):507-14, http:// dx.doi.org/10.1016/j.annepidem.2007.11.016.

61. Pong R, Pitblado J. Geographic distribution of physicians in Canada: Beyond how many and where. Ottawa: Canadian Institute for Health Information; 2005.

62. Weymouth S, Davey C, Wright JI, Nieuwoudt LA, Barclay L, Belton $\mathrm{S}$, et al. What are the effects of distance management on the retention of remote area nurses in Australia? Rural Remote Health. 2007;7(3):652.

63. Wilson NW, Couper ID, de Vries E, Reid S, Fish T, Marais BJ. A critical review of interventions to redress the inequitable distribution of healthcare professionals to rural and remote areas. Rural Remote Health. 2009;9(2):1060.
64. Grobler L, Marais BJ, Mabunda SA, Marindi PN, Reuter H, Volmink J. Interventions for increasing the proportion of health professionals practising in rural and other underserved areas. Cochrane Database Syst Rev. 2009;1, http:// dx.doi.org/10.1002/14651858.CD005314.pub2.

65. Seymour A, Dupre K. Advancing employee engagement through a healthy workplace strategy. J Health Serv Res Policy. 2008;13(suppl 1):35-40, http://dx.doi.org/10.1258/ jhsrp.2007.007031.

66. Pinikahana J, Happell B. Stress, burnout and job satisfaction in rural psychiatric nurses: A Victorian study. Aust J Rural Health. 2004;12(3):120-5, http://dx.doi.org/10.1111/j.14401854.2004.00572.x.

67. Pitblado JR, Medves JM, Stewart NJ. For work and for school: Internal migration of Canada's rural nurses. Can J Nurs Res. 2005;37:102-21.

68. Ilmarinen J. The work ability index (WAI). Occup Med. 2007;57(2):160, http://dx.doi.org/10.1093/occmed/ kqm008.

This work is available in Open Access model and licensed under a Creative Commons Attribution-NonCommercial 3.0 Poland License - http://creativecommons.org/ licenses/by-nc/3.0/pl/deed.en. 